\title{
DOCENCIA E INVESTIGACIÓN EN LA UNIVERSIDAD NACIONAL DE SAN JUAN (1994-2015): impacto del programa de incentivos a docentes-investigadores y la carrera del investigador científico del CONICET
}

\section{TEACHING AND RESEARCH AT THE NATIONAL UNIVERSITY OF SAN JUAN (1994-} 2015): impact of the incentive program to teachers-researchers and the career of the scientific researcher of CONICET

Victor Hugo Algañaraz Soria

(Consejo Nacional de Investigaciones Científicas y Técnicas, Universidad Nacional de San Juan, Argentina) victor.algz@gmail.com

Gonzalo Miguel Castillo (Consejo Nacional de Investigaciones Científicas y Técnicas, Universidad Nacional de San Juan, Argentina) castigonzalo@gmail.com

Recibido: $21 / 7 / 2017$ Aprobado: 15/12/2017

\section{RESUMEN}

A partir de un cruce analítico entre la perspectiva histórico-estructural latinoamericana y la reflexividad bourdiana, éste artículo procura caracterizar el cuerpo docente en la Universidad Nacional de San Juan (UNSJ) tomando como eje de análisis el impacto de dos de los instrumentos de promoción de la investigación más importantes en la historia del campo científico-universitario nacional: el "Programa de Incentivos a Docentes Investigadores" (PROINCE) y la "Carrera del Investigador Científico" (CIC) del CONICET. El estudio comprende una primera etapa que va desde mediados de los años '90 hasta la crisis nacional-global del 2001-2002, periodo en que gran parte del cuerpo docente se reconvirtió a las actividades científicas por efecto del PROINCE; y una segunda etapa, que va desde 2003 a 2015 cuando la institución evidenció un progresivo incremento de la cantidad de investigadores del CONICET. Partiendo del análisis de la bibliografía especializada disponible y el examen de una gran base de datos -que comprende al universo completo de sanjuaninos que integran la CIC y/o están categorizados en el PROINCE-, el trabajo avanzará articulando dos accesos metodológicos: uno de tipo "socio-histórico" anclado en la exploración de fuentes documentales; y otro de carácter "etnográfico" centrado en la recuperación del "testimonio" de actores claves de la institución: políticos, funcionarios de la universidad y docentes-investigadores. Entre los hallazgos más importantes, el artículo muestra que si bien la universidad fue consolidando en décadas recientes la labor de investigación como una opción profesional válida, ésta misma lógica alentó también procesos de asimetría entre disciplinas y unidades de investigación al tiempo que profundizó dinámicas diferenciadoras entre los mismos docentes-investigadores. Analizar el impacto de ambos programas en la UNSJ, evidenció la permeabilidad de su autonomía universitaria frente a las políticas científicas digitadas por los gobiernos de turno, a la vez que develó el impacto heterogéneo que los mismos tuvieron hacia el interior de la institución. En efecto, aunque de gran importancia el 
crecimiento exponencial del número de sus docentes-investigadores, no se ponderaron áreas de vacancia, ni fortaleció la investigación en las disciplinas menos desarrolladas.

Palabras clave: Docencia, Investigación, Universidad Nacional de San Juan, Programa de Incentivos a Docentes Investigadores, Consejo Nacional de Investigaciones Científicas y Técnicas.

\begin{abstract}
From an analytical cross between the Latin American historical-structural perspective and Bourdieu reflexivity, this article attempts to characterize the teaching staff at the National University of San Juan (UNSJ), taking as an axis of analysis the impact of two of the the most important promotion instruments for research in the history of the national scientificuniversity field: the "Program of Incentives for Teacher Researchers" (PROINCE) and the "Scientific Researcher Career" (CIC) of CONICET. The study includes a first stage that goes from the mid-1990s to the national-global crisis of 2001-2002, period in which a large part of the teaching staff was reconverted to scientific activities as a result of PROINCE; and a second stage, which goes from 2003 to 2015, when the institution evidenced a progressive increase in the number of CONICET researchers. Starting from the analysis of the specialized bibliography available and the examination of a large database -which includes the entire universe of sanjuaninos that integrates the CIC and/or are categorized in the PROINCE-, the work will advance articulating two methodological approaches: one "socio-historical" anchored in the exploration of documentary sources; and another of an "ethnographic" nature focused on the recovery the key actors "testimony" of the institution: politicians, university functionaries and teacher-researchers. Among the most important findings, the article shows that although the university was consolidating in recent decades the work of research as a valid professional option, this same logic also encouraged processes of asymmetry between disciplines and research units while deepening differentiating dynamics between the same teachers-researchers. Analyze the impact of both programs at the UNSJ, evidenced the permeability of their university autonomy against scientific politics directed by the current governments, while revealing the heterogeneous impact they had towards the interior of the institution. In fact, although the exponential growth of the number of its teachers-researchers, were not weighted vacancy, and was not strengthened research in the less developed disciplines.
\end{abstract}

Keywords: Teaching, Research, National University of San Juan, Incentive Program for Research Teachers, National Council for Scientific and Technical Research.

\title{
Introducción
}

Según la literatura especializada disponible ${ }^{1}$, el campo científico-universitario argentino se ha ido configurando históricamente como un espacio predominantemente público y a la vez heterogéneo. En efecto, más del 70\% de todas las actividades de investigación científica y desarrollo tecnológico (CyT) del país se desarrollan en organismos públicos o que mantienen vinculación con el Estado. Respecto a

\footnotetext{
${ }^{1}$ La preocupación por estudiar el complejo CyT argentino fue sistematizada en una obra clásica de Oteiza (1992) y más recientemente Hurtado (2010) hizo una importante contribución. Se destacan, también, los trabajos englobados en los estudios de ciencia, tecnología y sociedad (CTS) (Kreimer 2015; Vessuri 2006). Vinculada a esta visión, se encuentra una línea de estudios sobre las trayectorias y dinámicas de los organismos CyT que se complementa con el enfoque histórico y sociológico de la política científica y universitaria (Beigel et al.2016; Bekerman 2016; Vasen 2013; Carrizo 2012; Chiroleu, Suasnábar y Rovelli 2012; Albornoz y Gordon 2011; Prego y Vallejos 2010; Buchbinder 2010; Lugones y Hurtado 2010; Albornoz y Estébanez 2002; Myers 1992, entre otros). Pero aunque se trata de un campo de estudios en crecimiento, aún se carece de trabajos empíricos específicos: uno que, por ejemplo, aborde las características del circuito científico en San Juan. Precisamente, este artículo busca ser una contribución en esta dirección.
} 
la heterogeneidad, ha tendido a acentuarse recientemente y se ha manifestado, sobre todo, en torno a la escisión existente entre investigación y docencia, la distribución desigual de recursos entre instituciones y disciplinas y en las asimetrías de integración de los científicos en circuitos consagrados de publicación.

En este marco, se destaca el rol fundamental que vienen desempeñando las universidades nacionales. Hacia el año 2014, por ejemplo, la red de universidades públicas del país fue responsable de más de un cuarto del gasto en actividades CyT, concretamente \$ 7.892.991 mil pesos, del total nacional invertido. Para el mismo año, además, del total de 109.076 personas dedicadas a actividades de investigación científica en todo el país -incluidos personal técnico y becarios-, 52.478 (el 48\%) pertenecían a las universidades del Estado (MinCyT, 2016).

Sin embargo, el desarrollo CyT en cada una de las universidades públicas se halla atravesado por su emplazamiento geográfico, contexto histórico, marco institucional y por las necesidades e intereses de sus propias research capacities. De modo que, la importancia y el alcance que revisten estas actividades, varía taxativamente entre ellas. De allí, el interés de este artículo por concentrar la lente analítica en torno a una institución universitaria específica y muy poco estudiada hasta ahora: la Universidad Nacional de San Juan (UNSJ), en tanto principal organismo de educación superior y de desarrollo científico-tecnológico en la provincia.

El propósito general del trabajo es, precisamente, caracterizar los principales cambios sobrevenidos en la estructura del cuerpo docente de la UNSJ en décadas recientes, dando cuenta del peso relativo que fue adquiriendo la función de investigación. Se enfatizará, específicamente, en el impacto de dos instrumentos de política científica digitados a nivel nacional que se estima produjeron cambios profundos en el proceso de jerarquización de los docentes-investigadores de la institución: el "Programa de Incentivos a Docentes Investigadores" (PROINCE) impulsado por la Secretaría de Políticas Universitarias (SPU) en el marco de la compleja década de 1990 y la trascendental expansión que adquirió la "Carrera de Investigador Científico" (CIC) del Consejo Nacional de Investigaciones Científicas y Técnicas (CONICET) durante la última década y media. Se trata de dos de las iniciativas de promoción de la investigación más importantes en la historia del campo científico-universitario nacional que, como aquí podrá verse, tuvieron un impacto heterogéneo hacia el interior de esta universidad.

Es menester destacar que este artículo se desprende de un proyecto de investigación mayor, denominado: "El desarrollo de las 'research capacities' en la Universidad Nacional de San Juan (1973-2015): un estudio histórico-estructural sobre las relaciones y tensiones entre actores, disciplinas y políticas científicas” (PROJOVI UNSJ - Res. Nº 0338/FCS/2016) ejecutado entre 2015 y 2017 en el Instituto de Investigaciones Socio-económicas, Facultad de Ciencias Sociales de la UNSJ. De allí, que el análisis desplegado en el mismo esté sustentado en el marco epistemológico y conceptual ofrecido por el proyecto que, dicho en apretada síntesis, articula la "sociología reflexiva” de Pierre Bourdieu (1995), especialmente sus estudios sobre la autonomía del campo científico, con la tradición "histórico-estructural” latinoamericana y su mirada sobre los niveles de heteronomía con relación al campo de poder (Beigel, 2010). Para los fines de este trabajo, baste señalar que la clásica noción de "autonomía” bourdiana fue puesta en relación directa con observaciones empíricas sobre el desarrollo de los espacios de investigación científica y de educación superior en Argentina y particularmente en San Juan, viendo sus relaciones y tensiones con el campo de poder estatal. Nociones de ambas perspectivas serán puestas en juego complementariamente en varios pasajes del artículo, en pos de describir el impacto de políticas como el PROINCE y la CIC del CONICET en la UNSJ.

En línea con el proyecto, el artículo está sostenido por una estrategia metodológica de doble acceso: uno objetivo/descriptivo de tipo "socio-histórico" (anclado en la exploración de fuentes documentales y orientado a la reconstrucción de la historia reciente de la universidad) y otro subjetivo/comprensivo de carácter "etnográfico" (tendiente a reintroducir las experiencias, representaciones y disposiciones de los agentes implicados en la institución). Se trata de dos modos de conocimiento en permanente 
interacción, lo que Pierre Bourdieu (1995) ha llamado “relacionismo metodológico”. Por ello, sobre la base de un diálogo productivo con la bibliografía especializada disponible y el examen de una gran base de datos -que comprende al universo completo de sanjuaninos dedicados a actividades de CyT- ${ }^{2}$, el trabajo avanzará mostrando una articulación de aquellos dos accesos metodológicos.

La instancia objetiva, ha permitido trabajar con un "corpus documental" constituido a partir de la recuperación, problematización y puesta en relación no sólo de documentación oficial de nivel institucional/gubernamental (legislaciones universitarias, documentos de la SPU, del CONICET, del MINCyT, etc.), sino también de datos socio-históricos referentes a la misma UNSJ. Entre los principales documentos recuperados relativos a la universidad se destacan: la clásica obra sobre la historia y proyección de la institución (UNSJ, 1993), su Estatuto Universitario (2007 y 2011a), así como los informes de "Evaluación Externa” (CONEAU, 1998 y 2015) y el de “Autoevaluación Institucional” (UNSJ, 2011b).

En complemento, la instancia subjetiva ha implicado un acceso de tipo etnográfico basado en la realización de entrevistas en profundidad, bajo la vertiente de la "historia oral". Se trata de un procedimiento metodológico propio de la sociología histórica, basado en relatos verbales de individuos o colectivos sobre prácticas concretas vinculadas a periodos temporales acotados (Santamarina y Marinas, 1999). A lo largo del proyecto de investigación se han realizado, y examinado, más de veinte entrevistas a diferentes actores claves vinculados a la política científica desplegada en la UNSJ, seleccionados de acuerdo al proceso intencional, dinámico y secuencial que requiere la misma historia oral. Pero dado el carácter de este artículo y sus limitaciones de extensión, se optó por retomar en el texto el "testimonio" de algunos de estos entrevistados, con la finalidad de recuperar las experiencias y memoria contenidas en los relatos de quienes vivieron los acontecimientos en el seno mismo del espacio universitario. Así, el "corpus biográfico" desplegado en el trabajo es susceptible de ser clasificado en torno a tres grandes grupos, de acuerdo al perfil de los entrevistados: $1^{\circ}$-funcionarios de organismos del Gobierno vinculados al área de CyT; $2^{\circ}$-académicos de la universidad que ocuparon u ocupan cargos directivos en el área de investigación y $3^{\circ}$-docentes-Investigadores de la UNSJ provenientes de diferentes disciplinas, en tanto agentes vinculados directamente a la práctica científica.

Ambas instancias del relacionismo metodológico (objetiva y subjetiva) estuvieron integradas en un mismo acto de investigación y por tanto en las páginas que componen el trabajo se verá su articulación. Pues, como ha señalado Ferraroti:

\begin{abstract}
No se trata de colgar mecánicamente los jirones de experiencia humana, vivida y fechada como a un hipotético horizonte histórico, sino más bien la posibilidad de captar el nexo de condicionamiento recíproco que intercorre entre los diferentes niveles de experiencia y entre éstos y el plano macro sistemático estructural, de modo de fijar los primeros elementos de una dialéctica relacional en la que naturaleza y cultura, ambiente e historia, sistema, clase, grupo e individuo establezcan entre sí una relación necesaria y al mismo tiempo apriorística (dogmática) no exactamente (cuantitativa) previsible (1990: 100).
\end{abstract}

Queda por decir que el trabajo ha sido organizado en torno a cuatro apartados analíticos. En el primero de ellos, se presenta un recorrido selectivo y crítico por los principales constructos teóricos que guiaron la presente propuesta, y permitirán acercarse reflexivamente a la constitución y funcionamiento del campo científico-universitario en el país. El segundo muestra ya el aterrizaje

\footnotetext{
${ }^{2}$ La base de datos, que ha sido elaborada por el mismo equipo de investigación, incluye al universo completo de sanjuaninos que integran la CIC del CONICET y aquellos que están categorizados en el PROINCE. Su confección, fue posible mediante el rastreo, tratamiento y codificación de información proveniente de la misma institución y también del CONICET, la SPU y el PIDAAL (Programa de Investigaciones sobre Dependencia Académica en América Latina, con sede en la UNCuyo). La construcción, complejización y refinamiento de dicha matriz demandó varias jornadas de debate y discusión teórica, permitiendo elaborar un clasificador de las llamadas research capacities en la UNSJ. Entre las dimensiones de análisis comprendidas en dicha matriz, se encuentran: datos personales de los diferentes agentes investigadores (tales como género y edad), formación (títulos y fechas de egreso en los niveles de grado y/o posgrado), tipo de cargos docentes y/o de investigación en la Universidad, becas o cargos en el CONICET, categoría en el PROINCE, antecedentes en investigación (participación en proyectos, publicaciones y pasantías o estancias en el exterior), entre otras.
} 
empírico del trabajo en torno a la UNSJ, dando cuenta de las particularidades asumidas por la institución en el contexto. En cuanto a los dos subsiguientes, constituyen los apartados medulares del estudio y han sido ordenados cronológicamente: uno abarca desde mediados de los años 90 hasta la crisis nacional global del 2001-2002 y el otro desde el año 2003 hasta fines de 2015. Esta periodización comprende específicamente desde 1994, año en que comenzó a ejecutarse el PROINCE en la universidad, favoreciendo el desplazamiento de una tradición de investigación de carácter más vocacional -centrada habitualmente en las actividades de cátedra- en pos de un nuevo tipo de quehacer científico de los docentes más regulado institucionalmente. Luego, se tomará como punto de inflexión al año 2003, cuando la universidad comenzó a vivenciar un progresivo crecimiento de la cantidad de investigadores y becarios del CONICET, lo que impactó positivamente en la masiva conformación de equipos de investigación e incremento en los niveles de producción científica.

El análisis de ambos instrumentos de investigación permitirá poner en discusión la permeabilidad de la autonomía de la UNSJ frente a las políticas científicas digitadas por los gobiernos de turno, y en este sentido, la pregunta acerca de la capacidad endógena de la institución para retraducir la política científica nacional constituirá el hilo conductor del trabajo. Pues, aunque de gran importancia el crecimiento exponencial del número de sus docentes-investigadores, podrá verse que no se ponderaron áreas de vacancia, ni fortaleció la investigación en las disciplinas menos desarrolladas.

\section{Algunas consideraciones teóricas sobre la configuración del campo científico-universitario en Argentina}

El "campo científico” es, según Bourdieu (2003), un espacio de fuerzas dotado de una estructura y a la vez un espacio de luchas entre los agentes (es decir, los científicos, los equipos o los laboratorios) para conservar o transformar esa estructura. Estas luchas tienen por objeto la apropiación de un capital específico, aquello que está en juego: sean recursos económicos, honor social o influencia política. El capital específico del campo científico es la búsqueda del monopolio de la autoridad científica, esto es la "capacidad de hablar y actuar legítimamente (es decir, de manera autorizada y con autoridad) en materia de ciencia, que está socialmente reconocida” (Bourdieu, 2003: 76). Pero dicho capital, se encuentra desigualmente distribuido al interior del campo, por eso, existen dominantes y dominados. Cada agente se caracteriza por su trayectoria y su posición en el campo, el cual posee autonomía relativa, es decir, las luchas que en él se desarrollan tienen una lógica interna, pero también en cierto grado el resultado de las luchas externas (sean económicas, sociales, políticas, etc.) pesa fuertemente sobre él.

Precisamente, la cuestión sobre la autonomía del campo científico-universitario reviste gran particularidad en el caso argentino. Si bien es uno más entre los campos de producción simbólica del país (con sus cruces constantes con diferentes espacios de la producción cultural) se fue diferenciando de aquellos otros a medida que se fueron consolidando las redes de educación superior e investigación científica mediante la creación de nuevas universidades, institutos, agencias gubernamentales, etc. (Palamidesi, et.al, 2007). De allí que la estructura de dicho espacio se halle organizada, tradicionalmente, en función de dos grandes fuerzas: una exógena (vinculada a las históricas intervenciones - materiales y simbólicas- por parte de los gobiernos de turno y cristalizada en las diferentes políticas públicas destinadas al sector) y otra endógena (desplegada en el espacio de posibilidades que ofrece el estado de tensiones internas del mismo campo).

Al respecto, Fernanda Beigel (2010) ha señalado la existencia de una importante "elasticidad en los niveles de autonomía" del campo científico universitario-nacional, identificando tres usos diferentes de dicha noción. El primero de ellos estaría vinculado a la especialización de "lo académico" como espacio social, cristalizado en la institucionalización del sistema universitario y la creación de agencias públicas de investigación científica, dependientes del gasto público en educación superior. Esta primera noción se relaciona, así, con el concepto de "autonomía universitaria”. El segundo uso de la noción de autonomía se vincula con el proceso de institucionalización de las escuelas de enseñanza y diferenciación disciplinar, que repercutió directamente en la construcción de un capital simbólico 
específico y en la adquisición de disposiciones por parte de los agentes. La autonomía, en este caso, tiene que ver con la existencia de una illusio (un interés particular en el campo y en el objeto de apuesta) que diferencia al mundo académico de otros espacios del mundo cultural. Finalmente, el tercer uso de la noción de autonomía se refiere al impacto de la “internacionalización” y, específicamente, a la capacidad de los campos "periféricos” para desarrollar conceptos y agendas propias de enseñanza superior e investigación. Así, en contraste con el concepto de autonomía se erige el de "dependencia académica” referido a situaciones de dominación que devienen de la posición de un campo nacional en el sistema académico internacional.

En efecto, las fronteras del campo científico-universitario argentino han sido históricamente “elásticas” dado el peso relativo de procesos políticos y sociales nacionales e internacionales. La estructura y dinámica de dicho espacio no están definidas exclusivamente por las complejidades devenidas habitualmente en la construcción de un capital simbólico específico y por la adquisición de disposiciones y competencias por parte de los agentes intervinientes, sino también y en gran medida por la constante injerencia del Estado en los “asuntos internos” de las universidades y diferentes organismos de investigación.

En su obra Sur L'Etat (2012), el mismo Bourdieu ha señalado que una de las mayores dificultades del campo científico es instaurar una legitimidad independiente del campo de poder. De hecho, desde su perspectiva el mismo aparato del Estado también es concebido como un campo pero que ocupa una posición tal en la estructura general de los campos que condiciona en gran medida el funcionamiento de cada uno de estos. Se constituye, así, en el campo por excelencia o meta-campo" y como tal acumula un meta-capital específico: el "capital estatal” cuyo dominio (que implica una suerte de monopolización del monopolio) es objeto de luchas mayores que terminan configurando el entramado del campo de poder. La particularidad que reviste dicho capital es que tiene cierto poder sobre todas las otras especies de capital (sea el de fuerza física y coacción, el económico, el cultural, el científico, etc.) vigentes en los distintos campos. Es por esto que habitualmente los dominadores de diferentes campos sociales disputan fuertemente por ejercer un relativo "control” sobre el aparato del Estado.

En cuanto a los vínculos entablados entre las instituciones del campo científico-universitario y el Estado, Albornoz y Estébanez (2002) se concentran en torno al rol de las universidades y señalan:

\footnotetext{
Es propio del ámbito universitario, el ejercicio de una considerable autonomía por parte de los individuos, grupos y unidades académicas. (...) Pero también la universidad es un actor social que se vincula con otras instituciones como el Estado, el sector productivo, los movimientos sociales, e interviene en la lucha política que involucra a la sociedad en su conjunto. En lo particular mantiene relaciones de fuerte dependencia con el Estado, del cual provienen el marco legal de funcionamiento y el financiamiento. Otras instancias donde entra en juego la dimensión política del accionar universitario son, asimismo, el control de los recursos para la investigación, la disputa por el monopolio de la verdad científica, la gestión de la carrera académica (2002: 24-25).
}

Lo hasta aquí dicho coadyuva a poner en evidencia, la histórica relación-tensión entablada entre el Estado y las instituciones del campo científico-universitario en nuestro país que se ha expresado tradicionalmente en torno a la definición y ejecución de las diferentes "políticas científicas". Ello nos conduce, indefectible y permanentemente, a la pregunta siempre abierta en torno a la autonomía de la ciencia pública en Argentina. De acuerdo con Sarewitz (2004), las políticas científicas constituyen el proceso decisional a través del cual individuos e instituciones (principalmente Estados nacionales y provinciales) asignan y organizan recursos fiscales e intelectuales para potenciar e incentivar el desarrollo de actividades científicas y tecnológicas. En nuestro país las decisiones en materia de política científica han sido determinadas históricamente por modelos valorativos e ideológicos, y por tanto implican la aceptación de ciertas direcciones para la ciencia y la tecnología en desmedro de otras. Vessuri (1983) ha señalado que tales elecciones no son neutrales y que, de la misma manera, la ciencia que esas elecciones generan tampoco puede ser neutral.

Hasta aquí han sido definidos los puntos centrales de las perspectivas teóricas que guían el trabajo y en los apartados siguientes interesa avanzar centrando la lente analítica en torno a la UNSJ, institución 
específica del campo científico-universitario argentino, y reflexionar acerca de su capacidad endógena para retraducir la política científica digitada por los diferentes gobiernos nacionales en décadas recientes.

\section{La Universidad Nacional de San Juan en contexto}

La UNSJ ha desempeñado históricamente una posición de relevancia en el circuito provincial de producción científica, rol que ha tendido a acentuarse en el último tiempo. Si bien las sedes de los Institutos Nacionales de Tecnología Industrial (INTI); de Tecnología Agropecuaria (INTA); el de Prevención Sísmica (INPRES); así como el Ente Regulador de la Energía (EPRE) y la misma Universidad Católica de Cuyo realizan tareas específicas de investigación más desarrollo (I+D), es la universidad pública de San Juan el principal locus de educación superior y producción científica existente en la provincia. De hecho, en sintonía con otras universidades nacionales, apunta en su haber histórico el crédito de disponer del grueso de la capacidad científica local y como tal concentra la mayor cantidad de institutos, gabinetes, laboratorios, así como de recursos materiales y humanos (investigadores de tiempo completo provenientes del CONICET, docentes-investigadores categorizados en el Programa Incentivos así como becarios internos y externos) de la provincia dedicados a dichas actividades.

Según su estatuto, es una institución universitaria pública dedicada a la enseñanza de nivel superior, investigación, creación y difusión del saber (UNSJ, 2011a). Tanto su estructura académica como administrativa guarda similitud con el resto de las instituciones del sistema universitario nacional. Actualmente, está constituida por un Rectorado, cinco Facultades (Ingeniería; Ciencias Exactas, Físicas y Naturales; Filosofía, Humanidades y Artes; Arquitectura, Urbanismo y Diseño y Ciencias Sociales), una Escuela Universitaria en Ciencias de la Salud y tres establecimientos preuniversitarios. Sus dependencias centrales se encuentran radicadas en la capital de la provincia y en el Complejo Universitario Islas Malvinas (CUIM) con sede en la localidad de Rivadavia.

En torno a sus unidades académicas se cursan más de 60 carreras de grado (Licenciaturas, Profesorados y Tecnicaturas) y 30 de posgrado (Especializaciones, Maestrías y Doctorados). Pero, aunque las mismas están agrupadas bajo la figura habitual de Facultades, no se sigue una estricta lógica disciplinar. La Facultad de Ciencias Exactas no incluye, por ejemplo, a los Profesorados de Física, Química y Matemática, sino que éstos pertenecen a la Facultad de Filosofía, Humanidades y Artes, priorizándose así un aspecto pedagógico más que disciplinar o temático. Cada una de las Facultades está integrada a su vez por Departamentos (encargados de regular la función docente y la correspondiente labor académica) y diferentes unidades de investigación (encargadas de dinamizar las actividades CyT).

Sobre el personal docente, administrativos y el estamento estudiantil, la CONEAU ha señalado:

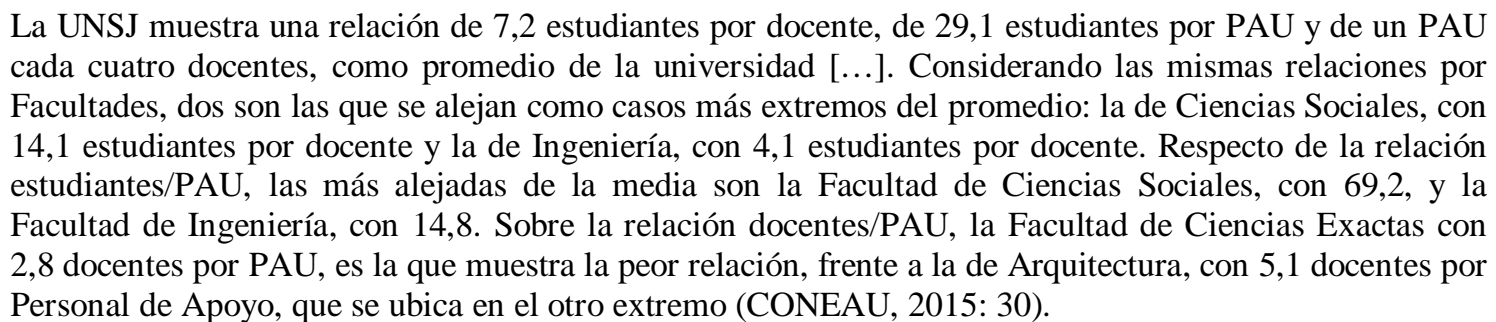

Respecto a la estructura del cuerpo docente, cabe destacar que la mayoría de los profesionales se desempeñan en cargos interinos o como suplentes y sólo alrededor del 30\% son efectivos. El plantel 
docente se halla relativamente envejecido y según los informes de evaluación interna y externa (UNSJ 2011 y CONEAU 2015) la dinámica de crecimiento docente en la universidad es muy débil ${ }^{3}$.

Según datos de la SPU, hacia el año 2013 la UNSJ contaba con un total de 3547 cargos docentes entre las jerarquías de Titulares, Asociados, Adjuntos, Jefes de Trabajos Prácticos (JTP) y Ayudantes de $1^{\circ}$ y $2^{\circ}$ categorías. Los mismos, al organizarse según su dedicación evidencian un rasgo importante: hay una predominancia casi absoluta de cargos con dedicación Simple en el conjunto de la universidad (1641), en detrimento de los cargos de dedicación Exclusiva (943). Al mismo tiempo, se advierte cierta concentración desigual de cargos según dedicaciones entre las Facultades. En efecto, existe una tendencia hacia una estructura docente con mayoría de cargos simples en el caso de la Facultad de Ciencias Sociales, mientras que inversamente la Facultad de Ingeniería tiende a concentrar una mayor cantidad de cargos exclusivos.

\begin{abstract}
La proporción de cargos exclusivos respecto al total de cargos es mucho más elevada en la Facultad de Ingeniería y en la Facultad de Ciencias Exactas, con 37,63\% y 31,50\% respectivamente, que en otras Facultades. En el otro extremo las Facultades de Ciencias Sociales y de Arquitectura son las que tienen los mayores porcentajes de cargos simples, con 50,09\% y 45,86\%, respectivamente. Los perfiles profesionales de los propios docentes se señalan como factor que incide en la existencia de bajas dedicaciones en Facultades como Filosofía, la cual tiene muchos Profesorados, y Ciencias Sociales, donde existen carreras como Ciencias Económicas y Abogacía, situación que estaría vinculada a características de esas profesiones, las cuales se asocian con una importante carga laboral externa (CONEAU, 2015: 56).
\end{abstract}

Otro aspecto a destacar es el nivel de formación del cuerpo docente en la universidad. Mientras que a fines de la década de 1990 sólo el 7\% contaban con formación de posgrado (Maestrías y Doctorados concluidos), dato que resultaba "especialmente negativo en las disciplinas básicas y en las carreras de mayor perfil científico” (CONEAU, 1998: 9); la situación comenzó a revertirse en años recientes, alcanzando un 20,5\% de docentes con posgrados concluidos hacia el 2013, concentrándose la mayoría de ellos en torno a la Facultad de Ingeniería (SPU, 2013).

En cuanto a la función de investigación, la misma asume la siguiente estructura organizativa y de gestión: una "Secretaría de Ciencia y Técnica" que depende del Rectorado y se ocupa de implementar las políticas de investigación y asignar los subsidios e incentivos económicos correspondientes; un “Consejo de Investigaciones Científicas y Técnicas y de Creación Artística” (CICITCA), integrado por los cinco secretarios de investigación de las Facultades y que procura organizar la función de investigación de acuerdo a la política científica predefinida y regular los diferentes instrumentos para su cumplimiento; las "Secretarías de Investigación" de las cinco Facultades, encargadas principalmente de identificar demandas y necesidades del medio para incentivar o reorientar el alcance de la investigación en sus ámbitos; y por supuesto las respectivas "Unidades de Investigación" (institutos, centros y gabinetes) con asiento en cada Facultad, compuestas por los distintos grupos de trabajo a cargo de los programas y proyectos CyT.

Actualmente, la universidad cuenta con 35 Institutos de Investigación distribuidos entre las 5 Facultades que la componen. En ellos se desarrolla la amplia mayoría de los proyectos de

\footnotetext{
${ }^{3}$ El marco regulatorio que determina la conformación del cuerpo docente en la UNSJ, comprende esencialmente al Estatuto Universitario (especialmente los artículos 114 al 132) y una serie de resoluciones y ordenanzas específicas que afectan directamente dicha función. La normativa más importante es la Ordenanza N²4/90 del Consejo Superior, que establece el reglamento de concursos para la provisión de cargos docentes ordinarios con carácter efectivo. No obstante, existe actualmente un proyecto de Carrera Docente en proceso de aprobación, luego de más de una década de tratamientos y reelaboraciones. En efecto, durante el primer semestre del 2017, el Consejo Superior de la Universidad aprobó por unanimidad dicho proyecto que, al entrar en vigencia, regulará los procesos de ingreso, promoción y permanencia de los docentes en la institución. Dicho proyecto, se encuentra actualmente en vías de tratamiento paritario, para el análisis y acuerdo de la parte sindical, quienes han realizado asambleas y encuestas de opinión en todas las Facultades para que puedan expresarse el conjunto de los docentes. Una de las novedades más importantes que incluye el mismo y que más polémica ha generado, es la incorporación de estudiantes (uno en carácter de titular y otro como suplente) en las comisiones evaluadoras (UNSJ, 2017).
} 
investigación, tanto de financiación interna como externa. Pero el $60 \%$ de estos institutos tienen asiento sólo en dos Facultades: Ingeniería y Ciencias Exactas. Las mismas concentran también los 5 Institutos de Doble Dependencia CONICET-UNSJ que existen en la provincia.

Ciertamente, desde su constitución como universidad nacional en Mayo de $1973^{4}$, la investigación científica y el desarrollo tecnológico han sido consideradas entre sus funciones centrales. Pero el proceso de institucionalización de dichas actividades reconoce diferentes etapas.

1973-1976: el quehacer científico de la universidad se sostuvo en gran medida con la tradición de algunas de las unidades preexistentes, tales como el Instituto de Investigaciones Mineras (1946); el Instituto de Investigaciones Hidráulicas (1947); el Observatorio Astronómico Félix Aguilar (1957); el Instituto Sismológico Volponí y el de Materiales y Suelos (creados en 1958); el Instituto de Investigaciones Arqueológicas y su Museo (creados en 1965); entre otros. Hacia 1973 se crearon los Institutos de Ingeniería Eléctrica (IlE) y Automática (INAUT) que alcanzaron gran desarrollo y prestigio en años posteriores.

1976-1983: la universidad fue intervenida militarmente y se desplegaron mecanismos de represión y control tendientes a lograr un repliegue del movimiento estudiantil, disminución de la matrícula y depuración del plantel docente (Algañaraz, 2014). Además, se intentaron cerrar algunas carreras (como la de Sociología) al tiempo que desmantelar ciertos espacios y áreas de investigación. Un claro ejemplo de ello, fue la clausura del proyecto "Fabricaciones Universitarias"5.

1983-1990: por efecto de la recuperación democrática, la UNSJ entró en una fase de reinstitucionalización de todas sus funciones y actividades. Recién en esta etapa comenzó a regularse lo relativo a las actividades de investigación y a implementarse verdaderas políticas promocionales. Si bien fueron años de creación de nuevos institutos y renovación de equipos de trabajo, terminaron por fortalecerse áreas disciplinares con reconocimiento y poder tradicional: el caso de Ingeniería, por ejemplo ${ }^{6}$.

A comienzos de los años 90, la universidad contaba ya con una veintena de nuevas unidades de investigación, entre las que se destacan: la Escuela de Caminos de Montaña y el Gabinete Topogeodésico (Facultad de Ingeniería); el Instituto de Geología “Emiliano Pedro Aparicio” (Facultad de Ciencias Exactas) y el Instituto Regional de Planeamiento y Hábitat (en la Facultad de Arquitectura, constituida entonces como un desprendimiento de la de Ingeniería), entre otros. Respecto a las Facultades de Ciencias Sociales y de Filosofía, crecieron menos en términos institucionales y se abocaron más bien a tareas de aplicabilidad de conocimientos. No obstante, en lo que sigue veremos que fue en décadas recientes cuando la universidad alcanzó un relativo afianzamiento de sus research capacities, por efecto de instrumentos como el PROINCE y la CIC del CONICET.

\footnotetext{
${ }^{4}$ La UNSJ fue creada el 10 de Mayo de 1973 en el marco del ambicioso "Plan Taquini”. Se constituyó, como tal, sobre la base de tres instituciones preexistentes en la provincia: la Facultad de Ingeniería, Ciencias Exactas, Físicas y Naturales (sede de la Universidad Nacional de Cuyo en San Juan), la Universidad Provincial Domingo Faustino Sarmiento (con funciones desde 1964) y el Instituto Nacional del Profesorado Secundario.

5 "Fabricaciones Universitarias" fue un emprendimiento científico que promovió la constitución de unidades productivas (como partes de aviones y autos) en la provincia. Se ejecutó en el marco de la Facultad de Ingeniería durante la gestión del Ing. Carlos Graffigna. La empresa trabajó vinculada al Instituto de Energía Mecánica y fue dirigida por el Ing. Domingo Leonetti (UNSJ, 1993).

${ }^{6}$ La Facultad de Ingeniería de la UNSJ goza tradicionalmente de un enorme prestigio a nivel local y gran reconocimiento nacional e internacional, cosechado sobre todo durante el primer gobierno peronista, cuando numerosos científicos de primer nivel provenientes de grandes Universidades Nacionales como las de Cuyo, La Plata y Buenos Aires se asentaron en San Juan y cimentaron una época de gran producción científica en la región, plasmada en la creación de los distinguidos institutos de investigación que hoy llevan el nombre de sus destacados investigadores precursores.
} 


\section{La función de investigación integrada al rol de docente: impacto del Programa Incentivos}

La llegada de Carlos Menem al poder del Estado significó para el sector CyT nacional, la emergencia de políticas de "innovación" moldeadas en un contexto de reformas estructurales de carácter neoliberal. El aparato gubernamental actuó más bien en detrimento de la tradicional autonomía tanto del CONICET como de las universidades nacionales: los embates padecidos por ambos frentes institucionales pusieron de manifiesto el desvalor social que se les atribuía a la educación superior y a la ciencia pública en este contexto. Se fue instaurando así una suerte de "Estado Evaluador" o giro hacia la “Autonomía Evaluada” (Buchbinder 2010; Krotsch y Atairo 2008) que implicó mayor regulación de estas instituciones vía financiamiento y evaluación.

Entre 1989 y 1996 tuvo lugar una etapa llamada de "reacción tradicionalista” en el terreno de CyT (Albornoz y Gordon 2013). En este marco, se autorizó el funcionamiento de 20 nuevas universidades privadas en el país y se creó la Secretaría de Políticas Universitarias (SPU) en 1993 dentro del Ministerio de Educación, constituyéndose en un actor clave para la mesa de negociaciones de las políticas científicas. Bajo su órbita se desplegó el Programa de Incentivos a Docentes Investigadores (o PROINCE, creado vía Decreto $\mathrm{N}^{\circ}$ 2427/93) como un paso crucial hacia una mayor regulación y orientación de las actividades docentes y de investigación en las universidades públicas (Chiroleu et al. 2012; Carrizo 2011). Todo ello decantó, primero, en la sanción de la Ley de Educación Superior N ${ }^{\circ}$ 24.521/95 que favoreció la segmentación del mercado académico y habilitó a las universidades a cobrar aranceles y, luego, en el surgimiento de la Comisión Nacional para la Evaluación y Acreditación Universitaria (CONEAU).

Posteriormente, entre 1996 y 1999, tuvo lugar una nueva etapa del gobierno de Menem en materia de CyT, llamada de “modernización conservadora”, caracterizada por el impulso de importantes reformas concretadas con financiamiento internacional: se creó la Agencia Nacional de Promoción Científica y Tecnológica (ANPCyT) para la promoción de proyectos de investigación y actualización tecnológica empresarial y también el Gabinete Científico-Tecnológico (GACTEC) con el propósito de mejorar la coordinación interministerial en actividades CyT (Rovelli 2015). Respecto al CONICET, fue intervenido y reformado durante esta etapa, generándose numerosos conflictos internos (Bekerman, 2016; Albornoz y Gordon 2011).

En cuanto a la UNSJ, su rasgo distintivo durante estos complejos años fue la implementación de "políticas promocionales" que funcionaron como instrumentos de apoyo al desarrollo CyT coadyuvando a desplazar las prácticas de investigación de carácter más vocacional vinculadas hasta entonces a las actividades de cátedra: subsidios para proyectos, becas internas de investigación (categorías estudiantes avanzados y graduados), becas externas de perfeccionamiento en posgrado y apoyos para asistencia a congresos y reuniones científicas, entre otros.

A razón del PROINCE, que comenzó a ejecutarse recién en el año 1994, gran parte del cuerpo docente en la universidad se reconvirtió a las actividades científicas y fueron emergiendo nuevas líneas de investigación al tiempo que se consolidaron las ya existentes.

El Programa consistía, básicamente, en otorgar un incentivo económico a los docentes de nivel superior que realizaran tareas de investigación. Para ello debían categorizarse previamente en función de una serie de requisitos vinculados a sus antecedentes académicos y desempeño en actividades científicas y docentes. El PROINCE, categorizaba a los docentes de las universidades nacionales en cuatro categorías según su productividad: A, B, C y D, reservándose las dos primeras para quienes contaran con una mayor cantidad de antecedentes y las dos últimas para quienes tuviesen menos.

Hacia mediados de los años 90, los docentes categorizados en la UNSJ que percibían el incentivo económico estipulado por el PROINCE eran cerca de 500, de los cuales menos el 20\% integraban las categorías A y B (SPU, 1996). Según la CONEAU: 
Con posterioridad a 1995 [...] se incorporaron aproximadamente doscientos docentes investigadores en la categoría $\mathrm{D}$, atribuyéndose este incremento a la existencia del incentivo, que ha hecho que prácticamente todos los docentes intenten integrarse a la investigación. Ello produjo cierta saturación de la oferta de proyectos, los que en gran número, sólo tienden a justificar el acceso al Programa de Incentivos. Es bajo el número de investigadores A con relación al total de docentes categorizados. [...] Asimismo es reducido el conjunto de A y B (135 según datos estadísticos de la SPU) en relación con el número de proyectos totales de investigación (257 según los datos que aportó la UNSJ). Esta correlación representa una atomización de los proyectos que parece tener más justificativos en la necesidad de participación por parte de los investigadores de categoría $\mathrm{C}$ y $\mathrm{D}$, que en una organización racional de los recursos de la Universidad (CONEAU, 1998: 16).

Hacia el año 1998, la categorización del PROINCE fue reformulada, estableciéndose los siguientes niveles: I, II, III, IV y V (SPU, 2002). Esta modificación procuró, principalmente, "aumentar la cantidad de docentes investigadores habilitados para dirigir proyectos de investigación acreditables, por lo que se incluye a la categoría III entre ellos” (Prati, 2003:106).

El gráfico siguiente evidencia la línea de crecimiento de los docentes-investigadores categorizados en la UNSJ:

Gráfico $\mathrm{N}^{\mathrm{0}}$ 1: Evolución de los docentes-investigadores de la UNSJ categorizados en el PROINCE, periodo 1994-2002. En valores absolutos.

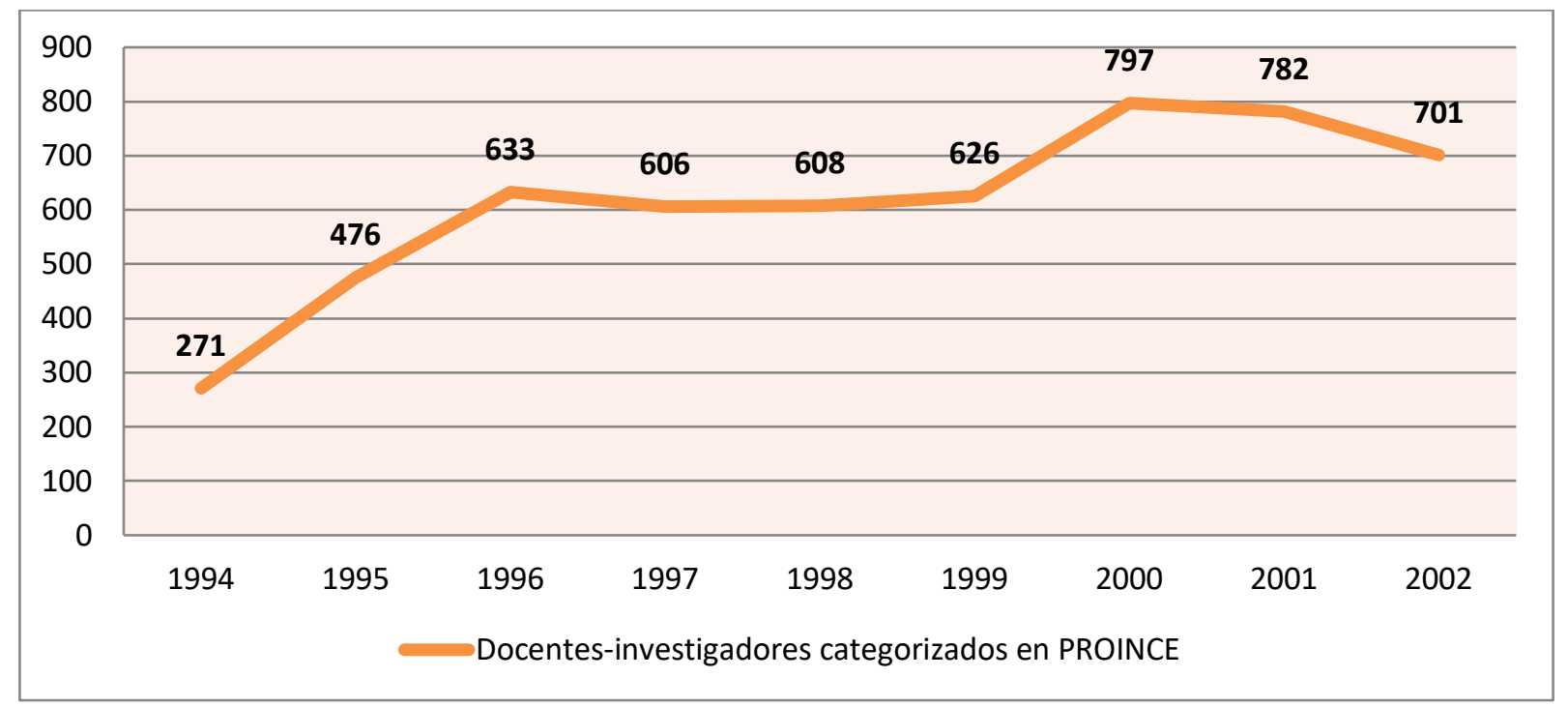

Fuente: Elaboración propia, en base a Anuarios de Estadísticas Universitarias (1996-2004).

El PROINCE tuvo un alto nivel de docentes-investigadores categorizados durante los primeros años de su implementación: desde 1994 hasta 1996 se manifestó una tasa de crecimiento de docentes categorizados prácticamente del 50\%. Desde entonces, la línea de progresión tendió a estancarse. Sin embargo, hacia el año 2000 se registró una gran cantidad de categorizados (797), pero la crisis nacional del año 2001-2002 marcó un nuevo descenso ${ }^{7}$. Una de las causas principales, radica en el giro migratorio de los docentes-investigadores, tal como señala la Esp. Mónica Coca, actual vicerrectora de la UNSJ, "existió una merma drástica de buenos profesionales que se fueron al exterior o que se fueron a trabajar a la parte privada. Hubo un desmembramiento de los recursos humanos formados académicamente que no podían vivir con el "sueldito" que se les daba” (Coca, entrevista, 2017: 9).

Gráfico Nº 2: Distribución de los docentes-investigadores del PROINCE en la UNSJ, según Categoría. Periodo 1994-2002. En valores absolutos.

\footnotetext{
${ }^{7}$ La línea de crecimiento de los docentes sanjuaninos categorizados en el PROINCE, comenzaría a recuperarse recién con posterioridad al año 2003: llegando a tener 692 categorizados en el 2004; 802 en el 2007; llegando a su punto máximo de 805 en el año 2010.
} 


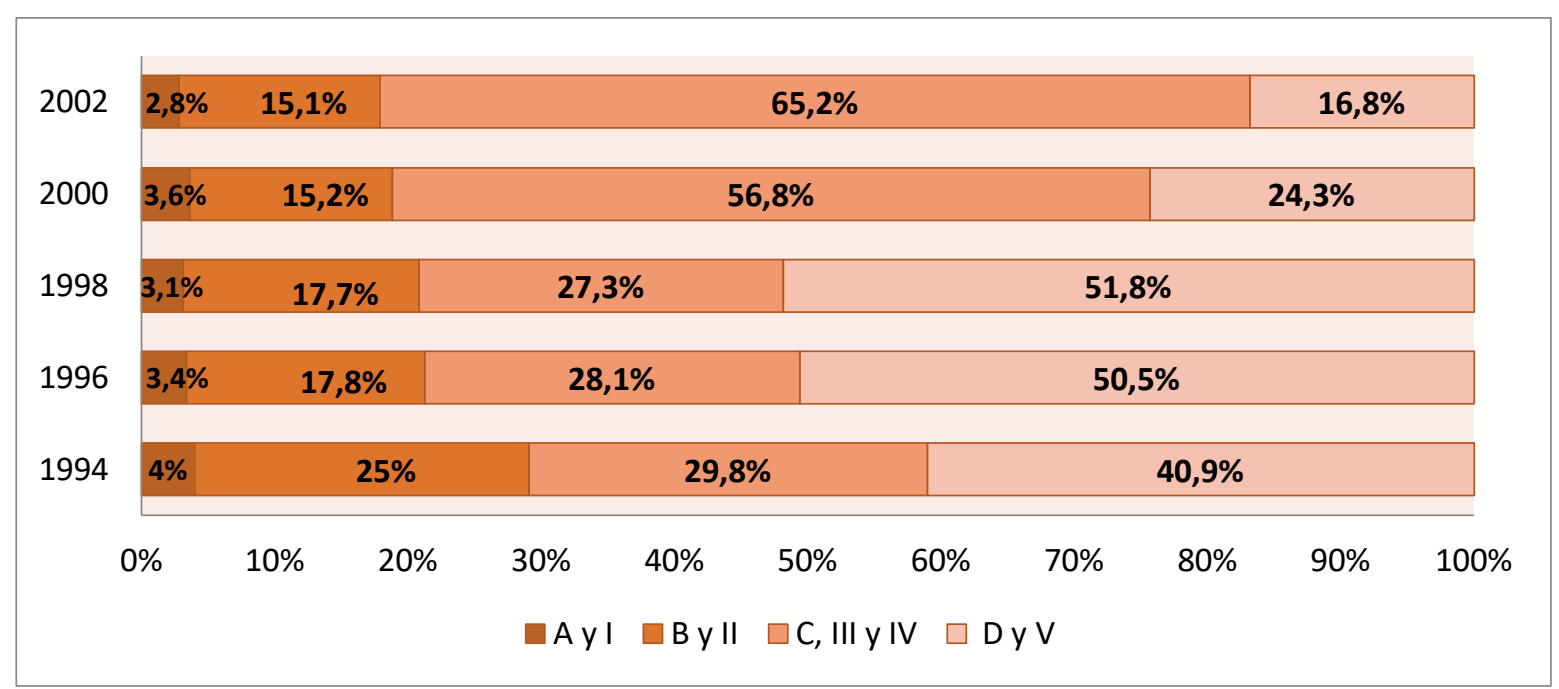

Fuente: Elaboración propia, en base a Anuarios de Estadísticas Universitarias (1996-2004).

Durante todo el periodo 1994-2002 se mantuvo como una constante la escasa cantidad de docentes investigadores con categorías A o I y B o II. Los primeros oscilaron entre el 2,85\% al 4,95\% mientras que los segundos entre el 15,1\% y el 25,1\%, siendo los valores más altos pertenecientes a los primeros años de vigencia del PROINCE. A su vez, en 1994 los categorizados en C o III y IV y en D o V llegaban al 71\%, mientras que en 1998, año en que se modifica la estructura de categorización, alcanzaron el 79\% y hacia el 2002 el 82\%. A partir del año 2000 los categorizados en D o V dejaron de ser mayoría y se evidencia una marcada alza en las categorías C o III y IV que para ese año representaban el 56,8\% y en el 2002 el 65,1\%.

El aumento desproporcionado de las categorías más bajas del PROINCE durante toda la década, permite comprender que el ingreso al mismo funcionó más bien como un refuerzo o inyección monetaria al salario que no se vio reflejado en el desarrollo científico de la institución. En efecto, hasta comienzos del nuevo siglo, la producción CyT de la universidad, sobre todo en las áreas humanas y sociales, asumió un carácter predominantemente local u endógeno. De manera que resultaba escasa la producción científica organizada según los parámetros de internacionalización, circuitos de consagración, uso de idiomas extranjeros, etc., tal como lo imponía el mismo sistema ${ }^{8}$.

Ahora bien, el PROINCE fue generando grandes tensiones al interior de la comunidad universitaria. De hecho, los mismos agentes universitarios han construido percepciones divergentes respecto a este dispositivo. La actual vicerrectora de la universidad expresó al respecto:

Fue altamente positivo, porque la docencia debe estar unida a la investigación, como el grado con el posgrado y por ende con la investigación. [...] Una notoria mayoría de docentes que no investigaban y comenzaron a investigar, descubrieron en la investigación el otro pie que le faltaba a su vocación docente (Coca, entrevista, 2017: 3).

En sintonía, el Dr. Ricardo Carelli, director del Instituto Nacional de Automática de la Facultad de Ingeniería, definió a este Programa como un generador de nuevas potencialidades en la actividad de la docencia y la investigación; sosteniendo que:

Permitió involucrar en actividades de investigación a numerosos docentes que no tenían previamente mayor motivación para hacerlo. Pero, se ha desvirtuado desde varios años atrás, debido a que los montos que se pagan como becas actualmente son insignificantes. Por otra parte, [...] la categorización de los investigadores, me pareció correcta (Carelli, entrevista, 2017: 6).

\footnotetext{
${ }^{8}$ Según Suasnabar y Rovelli (2010) la expansión de las actividades de la investigación constituye una de las tendencias que se inicia en los 90 en el marco más amplio de un cambio en el enfoque conceptual en las políticas de CyT, que resignificaron el papel central de las Universidades como productoras de conocimiento pero ahora dentro de los llamados “Sistemas Nacionales de Innovación”. Concepción que hunde sus raíces en la economía de la innovación y postula la necesidad de que las Universidades establezcan estrategias de vinculación con el sector productivo.
} 
Sin embargo, otros especialistas sostienen que el PROINCE generó efectos negativos al imponer una direccionalización a la actividad del docente universitario. Tal es el caso del actual Secretario de Ciencia y Técnica de la universidad, Dr. Mario Giménez, quien expresó: “el PROINCE me parece que fue desastroso. Fue lo que quizás llevó a que todo el mundo necesariamente tenga que estar involucrado en investigación cuando quizás no quiere, o que todo el mundo tenga que estar en docencia” (Giménez, entrevista, 2017: 7). En la misma línea, el Ing. Tulio del Bono (ex-Rector de la UNSJ, Secretario de CyT de la Nación entre 2003-2007 y actual Secretario de la cartera científica del gobierno provincial) considera que "es un error y fue un error del partido originario cuando se diseñó esto, obligar prácticamente a que todos los docentes fueran investigadores y que todos los investigadores fueran docentes” (del Bono, entrevista, 2017: 4). De manera similar, el Lic. Diego Fiol, Director del Instituto de Investigaciones Socio Económicas de la Facultad de Ciencias Sociales, (periodo 2008-2012) expresó al respecto:

\begin{abstract}
Varios no estábamos muy de acuerdo en la forma en que se aplicaba. Muchos de los que cobraban incentivos estaban felices, y los que no lo cobraban no. Entonces, lo que sucedía era que en un mismo equipo de investigación, algunos cobraban y otros no, y hacían el mismo tipo de actividades. Entonces, para quienes no cobraban se veía como una injusticia. Y el que lo cobraba, lo veía como un aumento de sueldo, no como un incentivo a la investigación. Lo incorporaba a su haber, no a la investigación. Yo creo que no estimulaba a la investigación. El que ingresaba al régimen de incentivos, salvo honrosas excepciones, creo que lo hacía más que nada para ganar unos pesos más (Fiol, entrevista, 2017: 2).
\end{abstract}

El Programa de Incentivos resultó cuanto menos conflictivo ya que estableció un tipo de asignación presupuestaria por mecanismos competitivos y meritocráticos que devino en una diferenciación salarial entre el personal docente. A su vez, generó una tergiversación y simulación de los indicadores de publicaciones para cumplir con los objetivos cuantitativos estipulados (Chiroleu et al. 2012; Carrizo 2011; Gordon 2013).

Es menester destacar que mientras la cantidad de docentes de la UNSJ categorizados en el PROINCE se incrementó notablemente durante los años '90, el vínculo construido entre dicha institución y el CONICET comenzaba a emerger aunque débilmente. Los escasos investigadores que lograron ingresar al Consejo durante estos años ${ }^{9}$ se caracterizaron básicamente por desempeñarse en áreas vinculadas a las denominadas “ciencias duras”.

En fin, hacia fines del siglo XX la universidad contaba con un total de 26 institutos de investigación, 6 centros y 9 gabinetes, más un observatorio astronómico, el Museo de Ciencias Naturales y la Escuela de Ingeniería de Caminos de Montaña que ejecutaban en total 257 proyectos de investigación en los que participaban alrededor de 720 docentes-investigadores (CONEAU 1998). Esta cifra representaba aproximadamente un 30\% del total del cuerpo docente que, vía el Sistema de Incentivos, atravesaba un franco proceso de reconversión hacia a las actividades CyT. Así, el modelo organizativo de la investigación que se fue gestando en la universidad, tuvo como pivote principal el número de institutos que se crearon y la cantidad de docentes investigadores categorizados, cuya mayoría correspondía al área de Ingeniería.

\title{
Acerca de la “expansión heterogénea” del CONICET en la UNSJ
}

Una verdadera bisagra en materia de CyT significó la crisis política y económica que sacudió estructural e institucionalmente al país hacia fines del 2001. Siguiendo a Albornoz (2004), la desinversión en el área fue una de las características que asumió el Estado en ese contexto: hacia el año 2000 la inversión argentina en CyT apenas alcanzaba el 0,42\% del PBI, mientras que países como Estados Unidos invertían el 2,68\% o Japón ya había superado el 3\%.

\footnotetext{
${ }^{9}$ Desde el año 1989 hasta el año 2002 ingresaron a la CIC del CONICET solamente 16 investigadores con lugar de trabajo en la provincia. Eso implica un promedio aproximado de un investigador por año.
} 
Pero, desde el año 2003 el campo científico-universitario nacional comenzó a recuperarse vivenciando hasta fines del 2015 un proceso de expansión sin precedentes de sus research capacities, basado en una fuerte inyección de recursos nacionales que replicó en una suerte de reconstrucción institucional de los organismos e instituciones de CyT (Beigel et al., 2016).

En efecto, la inversión en el área que había registrado un piso histórico en 2002 del 0,39\% respecto del PBI, recuperó recién en 2004 los valores previos a la gran crisis nacional, alcanzando un 0,52\% hacia 2008 y un ratio máximo histórico de 0.64\% en 2012 (MinCyT, 2016). Esta progresiva recuperación presupuestaria se materializó, entre otras cosas, en un notable aumento de cargos de dedicación exclusiva en algunas universidades, crecimiento del sistema de becas, política de repatriación de investigadores y fortalecimiento de las carreras de posgrado en todo el país. Aunque el rasgo más sobresaliente del periodo, fue tal vez la triplicación de la cantidad de investigadores del CONICET: entre 2003 y 2015 los investigadores aumentaron de 3.804 a 9.236. Respecto al conjunto de becarios del Consejo, pasó de 2.378 registrados en 2003 a 10.092 hacia 2015 (CONICET, 2016). Gran trascendencia tuvo en este contexto la creación del Ministerio de Ciencia, Tecnología e Innovación Productiva (MINCyT), que coadyuvó a consolidar el carácter público del campo científico argentino, a la vez que afianzó su rol como centro científico periférico. Nota de ello fue el trascendental apoyo del Estado a iniciativas soberanas como la producción y puesta en órbita de satélites geoestacionarios con un alto grado de componentes de fabricación nacional. No obstante, en simultáneo, gran parte de las investigaciones científicas desarrolladas en el marco estatal se encontraron sujetas a intereses impuestos desde las grandes potencias, un claro ejemplo de ello que aún persiste es la preponderancia de los parámetros estipulados por las revistas internacionales para medir el prestigio y la calidad de las publicaciones nacionales (Beigel et al., 2016; Albornoz y Gordon 2011). De manera que, fue profundizándose así una suerte de polarización entre científicos argentinos integrados a estilos de producción internacionalizados y aquellos que tienen una agenda más orientada a problemáticas locales.

El circuito científico en San Juan (cuya institución rectora ha sido tradicionalmente la universidad pública), no permaneció ajeno frente al nuevo escenario. La producción CyT adquirió gran protagonismo, sobre todo por los vínculos entablados con la Secretaría de Estado de Ciencia, Tecnología e Innovación del Gobierno de la provincia (SECITI) y el mismo CONICET. En cuanto a la SECITI, creada en 2012 por Ley $N^{\circ} 8.269$ con el propósito de darle rango ministerial a la actividad CyT local, viene ejecutando una importante cantidad de Programas y Proyectos en convenio con la UNSJ, entre ellos: el Programa IDEAS (Investigación y Desarrollo Aplicado); los PROJOVI (Proyectos de Jóvenes Investigadores); el Programa de Comunicación Pública de la Ciencia, los Proyectos de Investigación Orientados (PIO) en conjunto con el CONICET y las becas cofinanciadas también con UNSJ y CONICET. Respecto a este último organismo, la incorporación de San Juan entre sus zonas prioritarias coadyuvó a incrementar significativamente el número de becarios e investigadores en la provincia: los investigadores de la CIC aumentaron de 39 en 2007 a 91 hacia 2015. La cantidad de becarios también creció: en 2007 se contaban sólo 71 y para 2015 ya habían 191 (CONICET, 2016).

Pero si bien el nivel de ingresos de investigadores sanjuaninos a la CIC del CONICET se acentuó durante el interregno 2003-2015, los mismos se registran en la provincia con antelación al periodo de recuperación democrática abierto en 1983, aunque en niveles claramente inferiores. El gráfico siguiente, ilustra las fluctuaciones en la cantidad de ingresos según las variaciones en las políticas científicas de los gobiernos de turno durante el periodo estudiado. 
Gráfico No 3: Evolución de los Ingresos a la CIC del CONICET en la UNSJ, período 1989-2015. En valores absolutos.

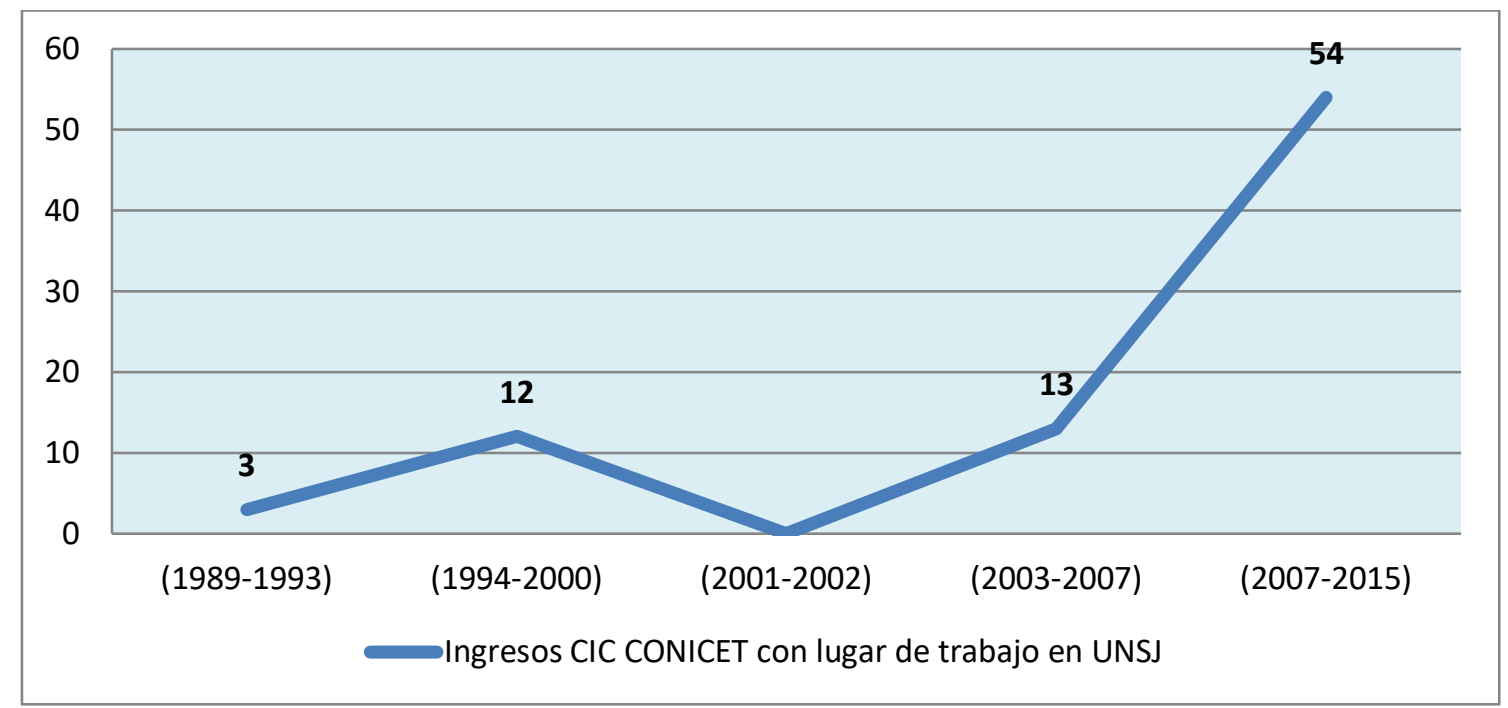

Fuente: Base de profesionales de CyT-UNSJ, de elaboración propia.

El gráfico precedente, permite identificar al menos 3 períodos relativos al ingreso a la CIC con rasgos distintivos. Una primera etapa, coincidente con los complejos años '90 donde el CONICET fue mantenido en jaque permanente y se promovió más bien el acceso al PROINCE: la mayor cantidad de ingresos al Consejo durante este periodo tuvo lugar entre 1994 y 1999, con 13 ingresos en 6 años. Se destaca, asimismo, otra etapa en la que no existieron ingresos de investigadores sanjuaninos a la Carrera del Investigador que se corresponde con la crisis del 2001-2002. Y además, hay un tercer período (2003-2015) que muestra un acentuado crecimiento respecto a los ingresos, mediado por la creación del MinCyT en el 2007.

Este impulso del CONICET, cristalizó en la reciente creación de un Centro Científico Tecnológico (CCT) en San Juan. El mismo, en palabras del Dr. Mario Giménez (actual Secretario de Ciencia y Técnica de la UNSJ), tiene por función principal:

\begin{abstract}
tratar de solucionar y encauzar toda la administración del CONICET en la provincia. [...] Tanto el funcionamiento como el financiamiento de los institutos de doble dependencia se canaliza por el CCT. Obviamente, recién estamos empezando. Hay universidades como Litoral, la UBA que tienen muchísimos institutos de doble dependencia. También son así los problemas que tienen. Nosotros tenemos 4 doble dependencias, son todos muy jóvenes. La mayoría no llevan 2 o 3 años desde que están funcionando. El CCT lleva un año y pico, recién se está empezando a constituir. Entonces, todo esto es nuevito. Por ahora hay mucha ansiedad de querer armar nuevos institutos de doble dependencia (Giménez, entrevista, 2017: 5).
\end{abstract}

Ciertamente, el CCT-San Juan se ocupa de administrar los proyectos del organismo a la vez que coordinar las actividades de los 5 institutos allí nucleados: el Complejo Astronómico "El Leoncito" (CASLEO) que data desde 1983 y los recientemente creados como doble dependencia "Instituto de Ciencias Astronómicas, de la Tierra y del Espacio" (ICATE, en 2009); el "Centro de Investigaciones de la Geósfera y la Biósfera" (CIGEOBIO, en 2012); en "Instituto Nacional de Automática (INAUT, también en 2012) y el "Instituto de Energía Eléctrica” (IEE, creado en 2014). Cabe destacar, que el CCT funciona dentro de las instalaciones de la misma UNSJ: los 3 primeros institutos tienen asiento en la Facultad de Ciencias Exactas, mientras que los dos restantes más la oficina administrativa en la de Ingeniería. 
Gráfico No 4: Distribución de investigadores del CONICET en San Juan, por área de conocimiento. Año 2015. En valores absolutos.

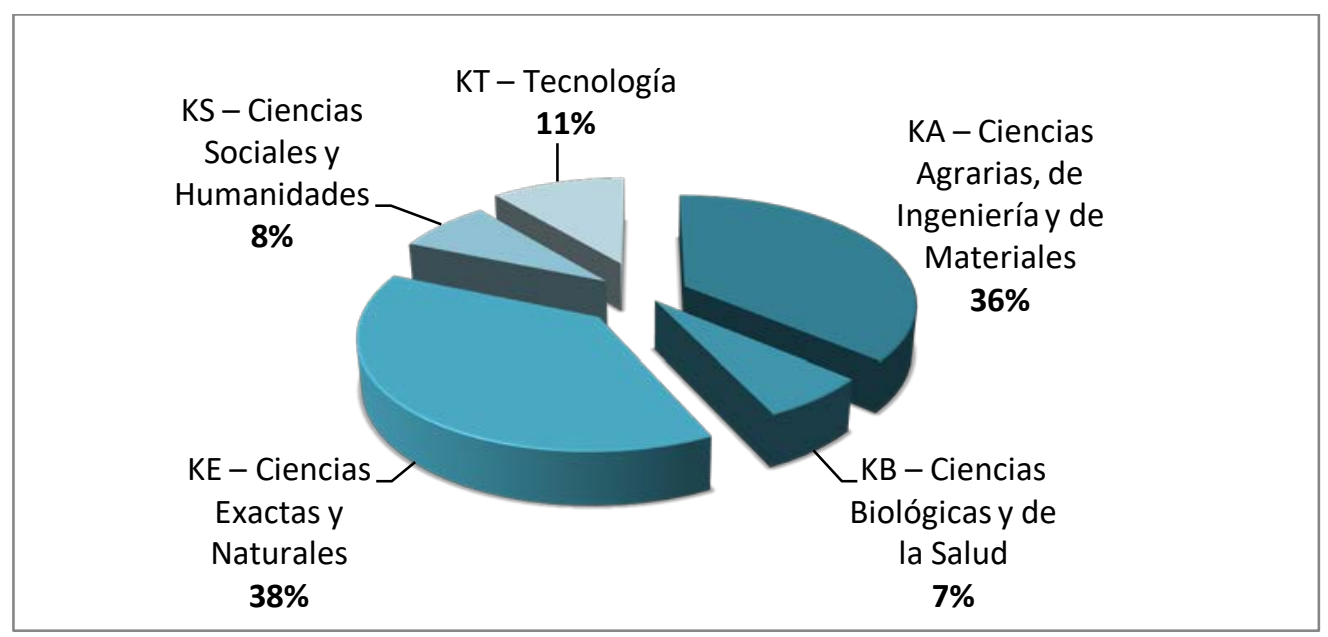

Fuente: Elaboración propia en base a CONICET (2016).

El gráfico anterior muestra la distribución de los 91 investigadores del CONICET registrados en la provincia hacia el año 2015, según las grandes áreas disciplinares delimitadas por el mismo Consejo. Puede verse que la mayor parte de ellos se concentran en torno a ciertas disciplinas reunidas en las llamadas tradicionalmente "ciencias duras" en desmedro de las Ciencias Sociales y Humanidades que continúan siendo un área de vacancia. De modo que, la expansión del CONICET no alteró la tradicional relación de fuerzas entre disciplinas científicas propia de la universidad pública.

Gráfico N 5: Investigadores del CONICET en San Juan, según dependencia del lugar de trabajo. Año 2016. En valores relativos.

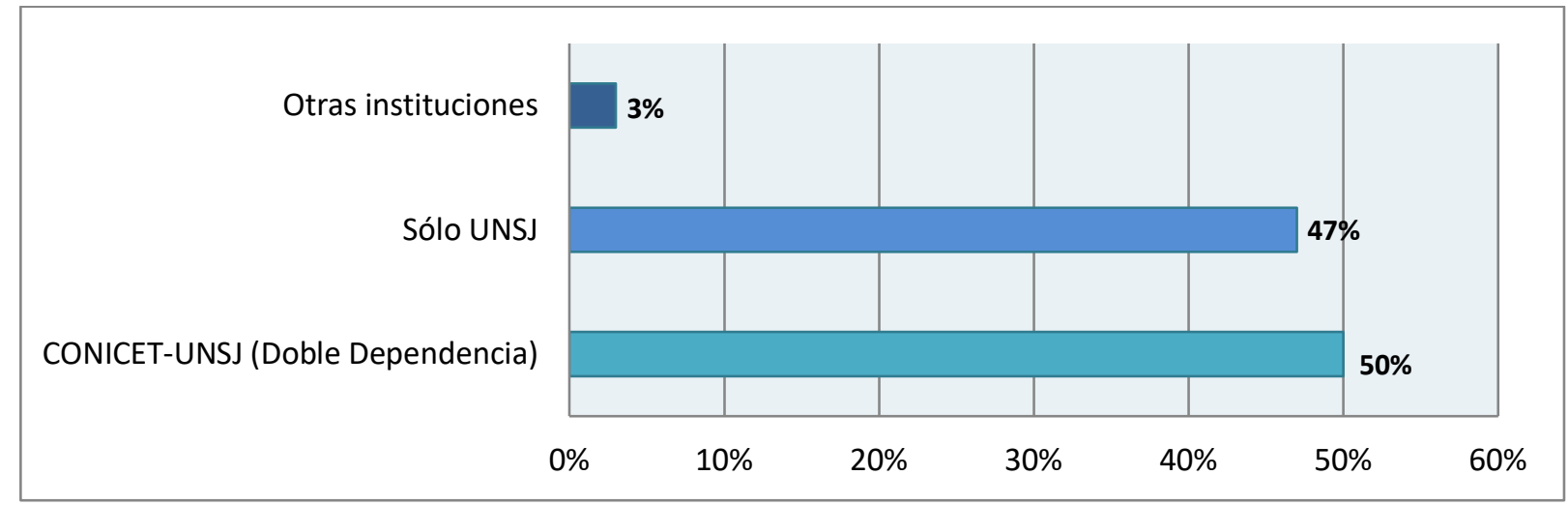

Fuente: Base de profesionales de CyT-UNSJ, de elaboración propia.

El grueso de los investigadores sanjuaninos que integran la CIC del CONICET se desempeña en el ámbito de la UNSJ (97\%), mayoritariamente en las Facultades de Ingeniería y en la de Ciencias Exactas: sea en las unidades de doble dependencia con CONICET que conforman el CCT (50\%) o en los institutos propios de la universidad (47\%). El 15\% de ellos cumplen funciones en el ICATE que es la unidad de investigación dependiente directamente del CONICET. Se evidencia así una tendencia completamente hegemónica de aquellas dos facultades respecto a las otras tres que en conjunto sumaban cuatro investigadores hacia el año 2015 (la de Ciencias Sociales registraba sólo uno). Existen, sin embargo, dos casos de investigadores con lugares de trabajos externos a la UNSJ: uno que desarrolla desde 1997 sus tareas en el Ente Provincial Regulador de la Electricidad (EPRE) y el otro desde 2007 en la Facultad de Ciencias Médicas de la Universidad Católica de Cuyo.

De lo hasta aquí dicho se desprende que si bien la expansión del CONICET en San Juan, y particularmente en la UNSJ, ha tenido un impacto altamente positivo durante la última década y media, el mismo ha sido desigual entre institutos y disciplinas. En efecto, las unidades de investigación 
correspondientes a las Facultades de Ingeniería y Ciencias Exactas han logrado afianzar su posición de privilegio hacia el interior de la institución universitaria y en el marco más amplio del circuito científico local. Resultado de ello fue la masiva conformación y/o consolidación de equipos de investigación en las mismas y el consecuente acrecentamiento de sus niveles de producción científica. Sobre el reconocimiento y prestigio que han cosechado algunas de ellas durante estos años, se refiere el Secretario de CyT de la universidad:

\begin{abstract}
Muchas de las áreas más reconocidas son tradicionales y están en las Facultades de Ingeniería y la de Exactas como Eléctrica, Automática, Hidráulica, la ECAM que es la Escuela de Caminos de Montaña, el Observatorio, el mismo Sismológico. Pero lo son porque tienen una cantidad de trabajos de servicio que son reconocidos en el ambiente. Pero hay otras de la Facultad de Filosofía, por ejemplo, que son reconocidas desde el punto de vista académico, docente [...] Los otros son reconocidos desde el punto de vista tecnológico o por el desarrollo de servicios que pueden prestar. En la Facultad de Sociales, por ejemplo, el Instituto de Investigaciones Socioeconómicas o el Administrativo Contable son muy reconocidos también pero en el ambiente más local. En la minería, por ejemplo, son reconocidos. El tema es que la prestación de servicio por ahí no es tan visible. Ellos tienen una visibilidad más local. [...] Eléctrica, en cambio, tiene trascendencia internacional. En toda Sudamérica está prestando servicios. Automática, por ejemplo, tiene la única co-titulación de electrónica que hay en Argentina y se está haciendo con Brasil. Pero son institutos de mucha tradición. Ingeniería tiene la mayoría de los institutos más antiguos, después hay algunos más jóvenes. Pero que no hay que quitarles su mérito, pero están más abocados a la parte académica y de docencia. Pero como que no terminan de visibilizarse a nivel nacional. No son tan visibles desde la Nación. Vos hablas a la gente del CONICET o de la Agencia y ya saben de Eléctrica, de Automática, etc. porque ya conocen los servicios que han tenido. Pero no quita que los otros sean de menor importancia, cada uno en su rubro (Giménez, entrevista, 2017: 10).
\end{abstract}

\title{
Reflexiones finales
}

Este trabajo procuró analizar los cambios sobrevenidos en la estructura docente de la UNSJ a razón de la implementación del PROINCE y la expansión de la CIC del CONICET en décadas recientes. El análisis de ambas iniciativas permitió poner de manifiesto la permeabilidad de la autonomía de dicha institución frente a las políticas científicas digitadas por los gobiernos de turno, a la vez que develar el impacto heterogéneo que tuvo lugar hacia el interior de la misma. Si bien la universidad, por efecto de ambos programas, fue consolidando la labor de investigación como una opción profesional (que fue válidamente aceptada en términos generales por los jóvenes graduados), ésta misma lógica alentó también procesos de fragmentación y asimetría entre docentes-investigadores, disciplinas y unidades de investigación.

En efecto, los procesos de reconfiguración del rol del docente universitario frente la función de investigación desde mediados de los años '90 hasta ahora, generaron diversas tensiones entre los docentes universitarios. El caso del PROINCE resultó paradigmático en este sentido: si bien el proceso de categorización condujo a un gran porcentaje de docentes a iniciarse en las tareas de investigación y fueron emergiendo nuevas líneas de trabajo, fue escaso el incremento de la producción científica misma. La incorporación de los docentes al Programa funcionó básicamente como un complemento salarial que no tuvo una contrapartida en los índices de desarrollo científico de la institución, sobre todo en las áreas humanas y sociales, que asumieron un carácter predominantemente local u endógeno.

Sobre las dificultades que generó el Sistema de Incentivos en la práctica, la Dra. Jimena Trotteyn, actual investigadora de CONICET y docente de la Facultad de Ciencias Exactas aducía: "si el docente debe hacer parciales, corregirlos, tomar exámenes, preparar las clases, aggiornar todos los conocimientos, etc. y, además, le pedís que haga investigación, muchas veces no le da la disponibilidad de tiempo, por ejemplo” (Trotteyn, entrevista, 2017: 5).

Respecto a los vínculos del CONICET con la universidad, se fortalecieron ampliamente durante los años 2003 al 2015, quedando cristalizados en la multiplicación de los recursos humanos y materiales avocados a la investigación científica. Sobre ello, el Ing. Tulio del Bono (ex-Rector de la UNSJ y actual Secretario de la SECITI) calificó como "muy sano que muchos investigadores de CONICET 
puedan trabajar en la universidad y, quienes tengan capacidad, puedan hacer docencia” (del Bono, entrevista, 2017: 6)

Empero, este crecimiento exponencial de docentes-investigadores en la estructura universitaria, no ponderó áreas de vacancia, ni fortaleció la investigación en las disciplinas menos desarrolladas. El crecimiento funcionó más bien como una plataforma de expansión que no trastocó la estructura inherente a las prácticas de CyT históricamente desarrolladas en la UNSJ. Hubo, en efecto, una preponderancia explícita de las denominadas "ciencias duras” con un alto nivel de participación en circuitos científicos nacionales e internacionales, en detrimento de las Ciencias Sociales, que ubicaron su producción/circulación, formación de recursos, y aplicación a proyectos en segmentos regionales y provinciales del campo científico durante todo el periodo en estudio.

Para finalizar, es menester señalar que las contradicciones y aspectos diversos que guarda históricamente la política científica nacional han tendido a acentuarse en el último tiempo. Así, el actual gobierno nacional ha puesto en discusión la orientación misma de la política científica y universitaria, ha cuestionado la expansión del campo y reducido drásticamente el financiamiento para el área de CyT. Ello impactó rápidamente en la actividad científica provincial, contrayendo por ejemplo, el número de investigadores que ingresaron al CONICET en la última convocatoria: mientras en 2015 ingresaron un total de 15 investigadores sanjuaninos, los ingresantes seleccionados en 2016 sólo fueron 5 (uno del área de Ciencias Sociales y el resto distribuidos entre Ingeniería y Ciencias Exactas). De modo que, a la concentración disciplinar se adiciona ahora un freno contundente al proceso expansivo.

Queda por decir que aunque abordar las políticas científico-universitarias nacionales excede el caso puntual de la UNSJ, se espera que las consideraciones aquí vertidas coadyuven a iluminar un espectro de investigaciones temporal y geográficamente más amplio. En efecto, la cuestión más general acerca de las distintas maneras de concebir las relaciones entre ciencia y docencia en la universidad, y las múltiples configuraciones de la política científica que de allí devienen, se reflejan en el caso, pero las conclusiones de su análisis esperan encontrar un alcance más amplio.

\section{Bibliografía}

ALBORNOZ M. y ESTÉBANEZ M. (2002). Hacer ciencia en la Universidad. En Pensamiento Universitario, 10(10), 19-33.

ALBORNOZ, M. y GORDON, A. (2011). La política de ciencia y tecnología en Argentina desde la recuperación de la democracia (1983 - 2009). En, ALBORNOZ, M. y SEBASTIÁN, J. (Eds.) Trayectorias de las políticas científicas y universitarias de Argentina y España. Madrid: CSIC.

ALGAÑARAZ, V. (2014). Reestructuración universitaria en clave autoritaria: política y accionar de los rectores de la Universidad Nacional de San Juan durante la última dictadura militar (1976-1983). En PolHis 7(14), 236-255. Recuperado de: http://polhis.com.ar/index.php/PolHis/article/view/19

BEIGEL, F. (2010). Autonomía y Dependencia académica: Universidad e investigación científica en Chile y Argentina (1950-1980). Buenos Aires: Biblos.

BEIGEL, F.; GALLARDO, O. y BEKERMAN, F. (2016). Institutional expansion and scientific development in the periphery. The structural heterogeneity of Argentina's academic field (1983-2015). En Minerva A Review of Science, Learning and Policy. London: Springer.

BEKERMAN, F. (2016). El desarrollo de la investigación científica en Argentina desde 1950: entre las universidades nacionales y el Consejo Nacional de Investigaciones Científicas y Técnicas. En Revista Iberoamericana de Educación Superior, 18,3-23. Disponible en https://goo.gl/9U5eGw 
BOURDIEU, P. (2003). El oficio de científico. Ciencia de la ciencia y reflexividad. Barcelona: Anagrama.

----. (2012). Sur l’ État. Cours au Collège de France 1989 -1992. Paris: Seuil et Raisons d’agir.

BOURDIEU, P. y WACQUANT, L. (1995). Respuestas por una antropología reflexiva. México: Grijalbo.

BUCHBINDER, P. (2010). Historia de las Universidades Argentinas. Buenos Aires: Sudamericana.

CARRIZO, E. (2011). Las políticas de CyT durante los años noventa: la triangulación entre el CONICET, la Secretaría de Políticas Universitarias, y la Agencia Nacional de Promoción Científica y Tecnológica en torno a la promoción de la investigación. Tesis de maestría en Política y Gestión de la Ciencia y la Tecnología. Buenos Aires: UBA. (Inédito).

CHIROLEU, A., SUASNÁBAR, C. y ROVELLI, L. (2012). Política universitaria en la Argentina: revisando viejos legados en busca de nuevos horizontes. Los Polvorines: UNGS-IEC-CONADU.

FERRAROTI, F. (1990). La historia y lo cotidiano. Buenos Aires: CEAL.

GORDON, A. (2013). La configuración de las políticas de ciencia, tecnología y educación superior en Argentina y Brasil en perspectiva comparada. En UNZUÉ, M. y EMILIOZZI, S. (Comp.) Universidad y políticas públicas ¿En busca del tiempo perdido? Argentina y Brasil en perspectiva comparada. Buenos Aires: Imago Mundi.

HURTADO D. (2010). La Ciencia Argentina. Un proyecto inconcluso: 1930-2000. Buenos Aires: Edhasa.

KREIMER, P. (2015). Los mitos de la ciencia: desventuras de la investigación, estudios sobre ciencia y políticas científicas. En Nómadas, 33 - 51.

KROTSCH P. y ATAIRO D. (2008). De la proliferación de títulos y el desarrollo disciplinario en las universidades argentinas. Buenos Aires: IPE-UNESCO.

LUGONES, G., HURTADO D., et al. (2010). El rol de las universidades en el desarrollo científico y tecnológico en la década 1998-2007. Chile: Universia-CINDA.

MYERS, J. (1992). Antecedentes de la conformación del Complejo Científico y Tecnológico, 18501958. En OTEIZA, E. La política de investigación científica y tecnológica en Argentina. Historias y perspectivas, 87-125. Buenos Aires: CEAL.

OTEIZA, E. (1992) La política de investigación científica y tecnológica en Argentina. Historias y perspectivas. Buenos Aires: CEAL.

PALAMIDESI, M.; SUASNÁBAR, C. y GALARZA, D. (2007). Educación, conocimiento y política. Argentina, 1983-2003. Buenos Aires: FLACSO Manantial.

PRATI, M. D. (2003) El impacto del Programa de Incentivos a partir de las "percepciones de los académicos. [Trabajo final de grado]. UNLP. Disponible en https://goo.gl/kdgxV7

PREGO, C. y VALLEJOS, O. (2010). La construcción de la ciencia argentina: instituciones, procesos y actores en la universidad argentina del siglo XX. Buenos Aires: Biblos.

ROVELLI, L. (2015). Un modelo para armar: áreas prioritarias e investigación en universidades nacionales. En Ciencia, Docencia y Tecnología, 26(51), 26 - 53. 
SANTAMARINA, C. y MARINAS, J. M. (1999) Historia oral. En Gutiérrez (coord.). Método y técnicas cualitativas de Investigación en Ciencias Sociales. Bs As: Síntesis Psicológica.

SAREWITZ, D., G. FOLADORI, N. INVERNIZZI y M. GARFINKEL (2004) "Science Policy in its Social Context”. In Philosophy Today, 2004, 67-83.

SUASNÁBAR, C. y ROVELLI, L. (2010). Gouvernance et réformes de l'éducation en Argentine récemment. En Revue internationale d'éducation de Sèvres. Sèvres: Centre international d'études pédagogiques, 55, 17-26.

VASEN, F. (2013). Las políticas científicas de las universidades nacionales argentinas en el sistema científico nacional. En Ciencia, Docencia y Tecnología. XXIV(46), 9-32. Disponible en: http://www.scielo.org.ar/scielo.php?script=sci_arttext\&pid=S1851-17162013000100001

VESSURI, H. (1983). La ciencia periférica. Caracas: Monte Ávila.

----. (2006). Universidad e investigación científica. Buenos Aires: CLACSO.

\section{Documentos}

CONEAU (1998). Informe Final Evaluación Externa de la Universidad Nacional de San Juan. Recuperado el 04 de julio de 2017 de: http://www.coneau.gov.ar/archivos/evaluacion/711-inf-final.pdf

CONEAU (2015). Universidad Nacional de San Juan. Informe de Evaluación Externa. Bs. As. $\begin{array}{lllllll}\text { Recuperado el } & 07 \text { de } & \text { Marzo }\end{array}$ http://www.coneau.gov.ar/archivos/libros evaluacion externa/52UniversidadNacionalSanJuan.pdf

CONICET (2016). Base de Datos del CONICET. Disponible en http://www.conicet.gov.ar/recursoshumanos/?graficoid $=44282$

MinCyT (2016). Indicadores de inversión en I+D. Disponible en http://indicadorescti.mincyt.gob.ar/

SPU. (1997). Anuario 1996 de estadísticas universitarias. Buenos Aires.

SPU. (2000). Anuario 1998 de estadísticas universitarias. Buenos Aires.

SPU. (2002). Anuario 1999-2000 de estadísticas universitarias: Universidades Nacionales. Bs. As.

SPU. (2005). Anuario 1999-2003 de estadísticas universitarias: Universidades Nacionales. Bs. As.

SPU. (2006). Anuario 2000-2004 de estadísticas universitarias: Universidades Nacionales. Bs. As.

SPU. (1998). Programa de Incentivo a los Docentes Investigadores: Régimen Legal. Buenos Aires.

UNSJ (1993). La Universidad Nacional de San Juan. Su historia y proyección regional. Tomo I y II. San Juan: EFU.

UNSJ (2007). Estatuto Universitario- Ordenanza Nº02/07-Asamblea Universitaria.

UNSJ (2011a). Estatuto Universitario- Ordenanza No 001/11-Asamblea Universitaria.

UNSJ (2011b). Informe de Autoevaluación Institucional de la Universidad Nacional de San Juan. Recuperado el 19 de mayo de 2015 de: http://www.unsj.edu.ar/descargas/InformeFinalAuto.pdf

UNSJ (2017). Proyecto de Carrera Docente aprobado por el Consejo Superior de la UNSJ. Disponible en https://drive.google.com/file/d/0ByQ1t6zzO8VhaEx1VGRiN3hwR0k/view 


\section{Entrevistas}

Entrevista a Dr. Mario Giménez [grabación], realizada en San Juan, abril de 2017. Archivo del equipo de investigación al que pertenecen los autores de este trabajo.

Entrevista a Esp. Mónica Coca [grabación], realizada en San Juan, abril de 2017. Archivo del equipo de investigación al que pertenecen los autores de este trabajo.

Entrevista a Dr. Ricardo Carelli [grabación], realizada en San Juan, abril de 2017. Archivo del equipo de investigación al que pertenecen los autores de este trabajo.

Entrevista a Ing. Tulio del Bono [grabación], realizada en San Juan, marzo de 2017. Archivo del equipo de investigación al que pertenecen los autores de este trabajo.

Entrevista a Lic. Diego Fiol [grabación], realizada en San Juan, abril de 2017. Archivo del equipo de investigación al que pertenecen los autores de este trabajo.

Entrevista a Dra. Jimena Trotteyn [grabación], realizada en San Juan en abril de 2017. Archivo del equipo de investigación al que pertenecen los autores de este trabajo. 